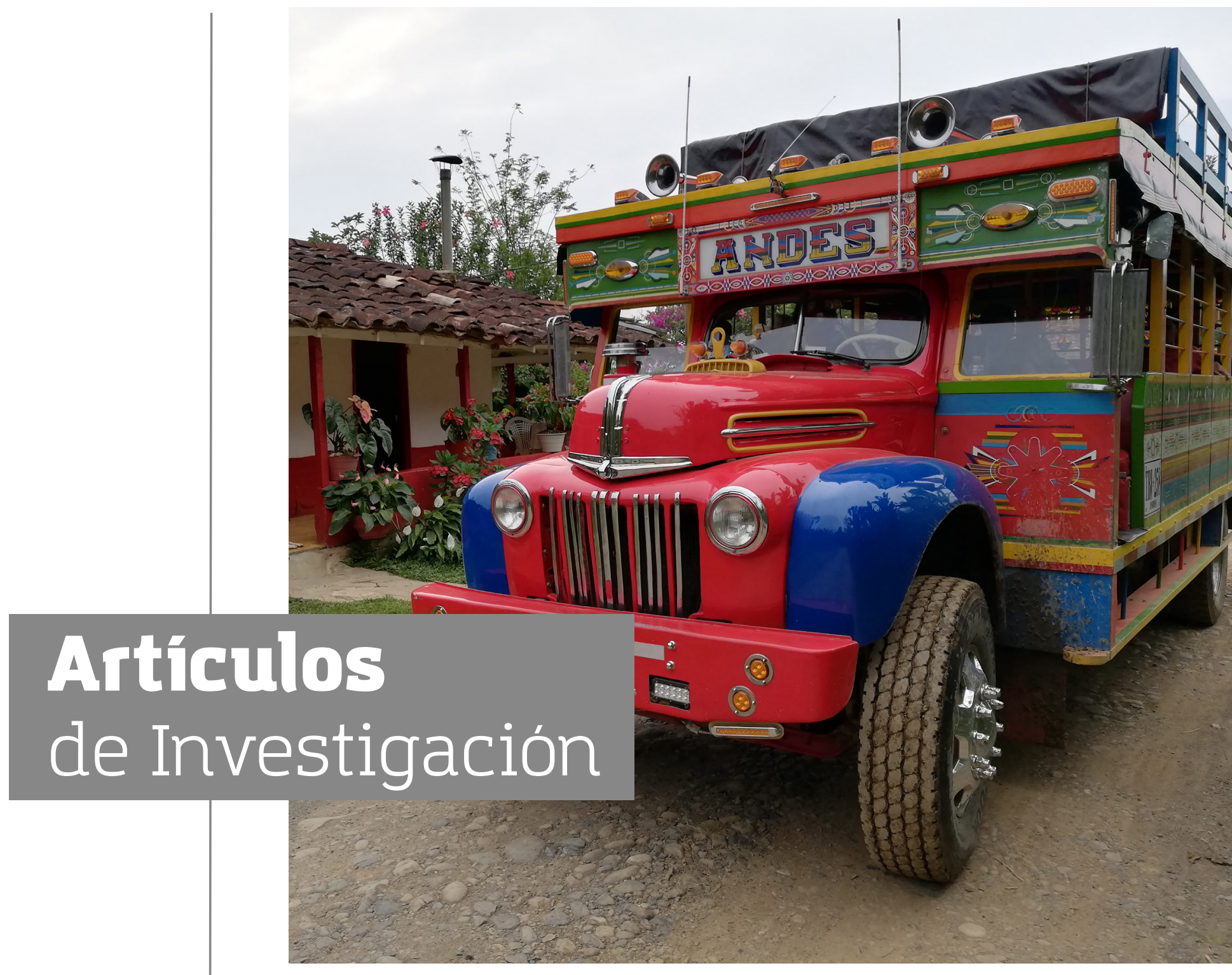




\section{Género, televisión}

\section{y poder en la Argentina \\ de hoy. La resemantización como estrategia \\ de reposicionamiento}

Gender, television and power in contemporary Argentina. The resemantization as a repositioning strategy

https://doi.org/10.18566/comunica.n44.a02

Recibido: 31 de enero de 2021

Aceptado: 25 de marzo de 2021

\section{Resumen}

La presente investigación tiene como objetivo describir y analizar las estrategias de resemantización en el campo televisivo argentino contemporáneo, las cuales operan como vehículos para la reproducción de las desigualdades entre varones y mujeres en dicho espacio social. Para ello, desplegaremos tres estudios de caso, que serán analizados desde la teoría sociosemiótica. Se entiende por resemantización la incorporación de significantes asociados a campos semánticos opuestos al que tradicionalmente se asocia la figura del sujeto que emprende dicho proceso. Los casos estudiados remiten a trayectorias mediáticas de hombres que se embarcaron en la resemantización de su propia figura con el fin de mantener su lugar de preeminencia en la televisión argentina. Vistos en perspectiva comparada, permitirán determinar que (i) la resemantización constituye una estrategia subrepticia que debemos atender a la hora de explicar la prevalencia de las desigualdades de género en los medios de comunicación; (ii) el grado de éxito de tal estrategia se encuentra correlacionado con el poder ostentado en el sistema de medios por quien la emprende. Si bien el análisis se circunscribe a escala nacional, la herramienta propuesta puede ser extrapolada a otros contextos. 


\section{Abstract}

This paper describes and analyzes the resemantization strategies in the contemporary Argentinean television field, which operates as vehicle for the reproduction of inequalities between men and women in that social space. We conceptualize the resemantization as the incorporation, by the subject, of signifiers belonging to opposite semantic fields. We will use three case studies, which will be analyzed from the socio-semiotic theory. These cases refer to the trajectories of men in mass media who embarked on the resemantization of their own figure in order to maintain their place of prominence on Argentinean television. From a comparative perspective, the analysis will show that: (i) resemantization constitutes a surreptitious strategy that must be attended when explaining the prevalence of gender inequalities in the media; (ii) the degree of success of such a strategy is correlated with the power held in the media system by the person undertaking it. Although the analysis is limited to a national scale, the proposed tool is capable of being extrapolated to other contexts.

\section{Introducción}

Los estudios que anudan medios de comunicación y género han seguido una misma tendencia. Desde la década de 1970 contamos con líneas de investigación que reflexionaron sobre esta intersección y que, hoy en día, ofrecen sustento empírico sólido para algunas afirmaciones: las jerarquías de género forman parte del sistema de medios de comunicación y cristalizan empíricamente en la subrepresentación de las mujeres (Vega Montiel, 2014), en el salario menor que estas perciben respecto del de los varones que cumplen tareas semejantes (Pontes, 2017) y en la reproducción de estereotipos de género sexistas (García Beaudoux, 2018), un fenómeno que atraviesa tanto a países en desarrollo como a países desarrollados.

En este marco, nuestro objetivo consiste en describir y analizar las estrategias de resemantización en el campo televisivo (Bourdieu, 1996) que operan como vehículos para la reproducción de las desigualdades entre varones y mujeres en dicho espacio social. Para ello, desplegaremos tres estudios de caso partiendo de la teoría sociosemiótica. Estos casos remiten a diferentes trayectorias mediáticas de hombres que se embarcaron en la resemantización de la propia figura, con el fin de mantener su lugar de preeminencia en la televisión argentina. Los mismos fueron seleccionados para poner en primer plano los efectos de la diferencia de poder sobre el éxito prospectivo de la resemantización: a menor poder, mayores son las dificultades para imponer el cambio de sentido. comunicación

número 44

Enero - junio

2021

Género, televisión, sociosemiótica, resemantización, Argentina. po político, América Latina.

\section{Keywords}

Gender, television, sociosemiotic, resemantization, Argentina.
1 Tanto es así que dio lugar a la emergencia de organismos internacionales como la Global Alliance on Media and Gender (dependiente de la Unesco). 
En un contexto social en el que los movimientos feministas ocupan un espacio cada vez más central de la arena pública argentina, es de esperarse que quienes gozan de un lugar de preeminencia en la televisión busquen adaptarse a las nuevas reglas de juego, caracterizadas por una baja abrupta del umbral de tolerancia a distintas formas de violencia machista y desigualdad basada en el género (Faur, 2017). Considerando el devenir de tal escenario, mostraremos longitudinalmente las operaciones de asignación de sentido mediante las cuales se ensayan las estrategias de resemantización del propio sujeto a partir del análisis de tres trayectorias de hombres en los medios: la del actor de telenovelas Juan Darthés, del conductor televisivo Jorge Rial y del conductor y empresario Marcelo Tinelli.

Las herramientas analíticas son de carácter cualitativo. Si bien existen investigaciones que confirman el lugar de subalternidad al que las mujeres son relegadas en los medios de comunicación, entendemos que es necesario un análisis de fondo sobre los procesos que conducen a dicha situación. Las desigualdades de género remiten a relaciones empíricas, numerosas y muchas veces difíciles de generalizar; en términos de Jelin et al. (2017), las diversas categorías y dimensiones de desigualdad se entrelazan en múltiples escalas. Es por esto que proponemos un instrumento flexible que ayude a complementar los estudios que hoy nutren al debate de datos cuantitativos (información sociolaboral de las mujeres en los medios, sobre el tiempo que ocupan en pantalla, análisis de contenido, etc.) con nueva evidencia que permite explorar rasgos procesuales del fenómeno. Esto no implica reducir las causas de la desigualdad persistente a la resemantización, sino que apunta a incorporarla a un entramado complejo y multidimensional de causas, para darle su lugar en la construcción simbólica de la desigualdad (Reygadas, 2020).

Lo que viene a continuación consta de dos partes. La primera presenta las coordenadas teórico-metodológicas que sustentan el dispositivo analítico propuesto para el estudio. La segunda aborda el análisis de los tres casos, su evolución en el tiempo y los efectos de los distintos niveles de poder de los sujetos.

\section{Coordenadas teórico-metodológicas}

En esta investigación partimos de la teoría sociosemiótica, que considera al sentido bajo la forma de producción social, la cual se encuentra sujeta a condiciones de producción tanto discursivas como extradiscursivas. Ello implica concebir los fenómenos de sentido apareciendo, por una parte, bajo la forma de conglomerados de materias significantes, y remitiendo, por otra, al funcionamiento de la red semiótica conceptualizada como sistema productivo (Verón, 1998, p. 124). Simultáneamente, entra al análisis 
una perspectiva longitudinal con el objetivo de evidenciar la variación de sentidos sociales asociados a determinados sujetos a lo largo del tiempo.

Los conceptos de "materia significante" y "sistema productivo" son centrales para el análisis. El primero refiere a la materialidad que presentan todos los discursos y que en gran medida establecen su naturaleza y los modos de producción-circulación-recepción. El segundo lo hace en relación con las condiciones de producción de todo discurso (Verón, 1998, pp. 127 y ss.).

En este trabajo es necesario considerar las marchas y movilizaciones masivas bajo la consigna \#Niunamenos acontecidas en Argentina en 2015 como condiciones de producción. Dichas movilizaciones exigían posicionamientos claros frente a la violencia y desigualdad de género; entre las principales temáticas abordadas se encontraban el incremento de feminicidios aunados a la sensación de impunidad, la violencia doméstica, la interrupción legal del embarazo y el acoso en los espacios de trabajo, entre otras (Chenou y Cepeda-Másmela, 2019; Gago, 2019). La presión social de la opinión pública afectó no solamente a jueces y políticos, sino que permeó en la agenda de los principales medios de comunicación. Un efecto casi inmediato fue, como veremos, las operaciones de resemantización emprendidas por diferentes sujetos mediáticos que buscaban así empalmar con los reclamos sociales y, consecuentemente, conservar su lugar dentro del campo mediático.

En cuanto a la materialidad de los cuerpos, en este trabajo partimos de la base de que su corporalidad puede entenderse como materia significante, lo cual posibilita analizar en sus propias figuras el proceso de resemantización (lo veremos a continuación). Paralelamente, como ya dijimos, las marchas y movilizaciones sociales son conceptualizadas como condiciones de producción que inciden en los sujetos y que explican tales operaciones.

Para entender el proceso de resemantización es preciso considerar al sujeto en sí mismo como un conjunto de unidades semánticas capaces de producir y transmitir significados, y, por eso mismo, de generar sentido (Maier, 2008, p. 43). De allí que se entienda dicho proceso como aquel mediante el cual un sujeto incorpora significantes pertenecientes a campos semánticos opuestos al que tradicionalmente se le asocia. Esa incorporación transcurre siempre a lo largo del tiempo y en contextos sociales específicos, por lo cual su resultado final es incierto y el análisis del proceso deberá ser longitudinal.

En el presente trabajo proponemos que los significantes mencionados deben ser vistos como un conjunto de unidades semánticas interrelacionadas. Unidades que se encuentran posicionadas en un sistema social e histórico de oposición o complemento, el cual les confiere carácter de interpretantes (Eco, 2016, pp. 121 y ss.). Por tanto, el sujeto puede ser entendido como 
un continuum material sobre el cual se recortan diferentes unidades semánticas. De esta forma, el campo semántico de los sujetos se entiende como conformado por el conjunto de las relaciones entre marcas semánticas interrelacionadas. De todas ellas, las que nos interesa rastrear y describir son las que generan el proceso de resemantización, es decir, aquellos significantes cuyos significados pertenecen a campos semánticos opuestos y que, con su variación a lo largo del tiempo, pueden generar (o no) reposicionamientos dentro del ámbito televisivo. Para ello tomamos como categorías de análisis los aditamentos, la propia corporalidad de los sujetos y el contexto de enunciación.

- Aditamentos. Refiere a los objetos que el sujeto incorpora a su figura y que operan en la relación intersubjetiva con base en su significado socialmente compartido.

- Corporalidad. Refiere a la característica de los cuerpos de ser, a la vez, significantes y sintientes (Leunda, 2015). Es el correlato de la incapacidad de controlar absolutamente la propia corporalidad, del hecho de que, en la interacción social, una situación pueda hacer que el cuerpo genere significaciones incluso contrarias a las buscadas conscientemente por el propio sujeto. Como veremos, esta categoría no es inmediatamente aprehensible, como sí lo es la anterior, pero en ciertas situaciones cobra importancia heurística.

- Contextos de enunciación. Refiere al espacio desde el cual cada sujeto enuncia su posición o, lo que es lo mismo, pone a circular un conjunto de significados que, con las consideraciones mencionadas, pueden ser leídos en tanto operaciones de resemantización. En dichos espacios los sujetos se construyen a sí mismos como enunciadores, a la vez que construyen también la relación con sus enunciatarios, sean estos sus interlocutores o los propios televidentes.

Como puede apreciarse, no hemos mencionado el discurso como categoría analítica. Esto es así porque entendemos que es transversal a cada una de ellas. En efecto, este trabajo se aleja de la concepción puramente verbal del discurso y se enfoca en cambio en las propiedades significantes, sean estas objetuales (aditamentos), corporales, contextuales o verbales. Por tal motivo, si bien el análisis de "lo que se dice" reviste importancia analítica, siempre es en relación con las tres categorías aquí propuestas, y no con base en su propia inmanencia.

Finalmente, es importante señalar que los significantes utilizados para el análisis fueron escogidos debido a su potencial heurístico y de ningún modo agotan la totalidad que puede hallarse. Dado que la resemantización es aprehensible solo habida cuenta de un análisis longitudinal, hemos optado por presentar los casos en la forma de trayectorias de los sujetos en relación 
con cuestiones de género. A fines comparativos, los casos seleccionados se corresponden con personalidades mediáticas argentinas que revisten distintos niveles de poder dentro del campo.

\section{Descripción y análisis: tres estudios de caso}

A continuación, la evolución del proceso de resemantización a lo largo de la trayectoria profesional de los sujetos tomados como casos, poniendo en relieve los cambios y su grado de aceptación o rechazo. Cada uno de ellos reviste distinto nivel de poder, lo cual, entendemos, tiene una incidencia insoslayable sobre la suerte de la resemantización: uno es actor, otro conductor televisivo y otro empresario de medios y conductor. Resulta importante señalar que la descripción y análisis longitudinal están orientados por hitos: es decir, las trayectorias y sus respectivos procesos de resemantización son repuestos a partir de acontecimientos clarificadores y representativos (no estamos aquí frente a biografías exhaustivas).

\section{El actor Juan Darthés}

El caso de Juan Darthés (55 años) representa el fracaso de las estrategias de resemantización. Se ha desempeñado como actor desde los 20 años, con diversos papeles para la televisión, el cine, el teatro y las miniseries, además de desenvolverse como cantante (con un total de nueve discos, la mayoría dentro de la banda sonora de las series que protagonizaba). A partir de 2013 el actor estuvo esporádicamente bajo escrutinio público por la salida abrupta de la actriz Carla (Calu) Soledad Rivero de la telenovela Dulce amor (2012-2013). Comenzaron a correr rumores sobre un supuesto caso de acoso sexual por parte de Darthés, quien era su pareja en la ficción televisiva, y ante el silencio de la actriz, el actor fue cuestionado por periodistas de medios del espectáculo. A mediados de ese año, y por presión de la abogada del actor, la actriz aclaró en un tuit que no hubo acoso sexual, para así evitar una demanda por daños y perjuicios (volveremos sobre este caso más adelante). Al poco tiempo el tema perdió trascendencia en la agenda mediática, aunque posteriormente volvería a la discusión pública.

Luego, en un contexto social de creciente movilización, el actor llevó a cabo dos actos que lo posicionaron del lado del reclamo de las mujeres, en sintonía con el comportamiento de otros sujetos del ámbito mediático y político. El primero de ellos fue un tuit. Como hemos mencionado, en 2015 se produjo una movilización masiva bajo la consigna \#Niunamenos, la cual buscaba evidenciar la violencia y desigualdad de género presentes en la sociedad argentina, al tiempo que exhortaba a insertar la problemática en la agenda pública. 
El 28 de mayo, una semana antes del día de la movilización y en medio de un ambiente convulsionado por las repercusiones y adhesiones que generaba el movimiento, Darthés publicó en su cuenta de Twitter una fotografía suya sosteniendo un cartel blanco con la consigna \#Niunamenos, acompañada únicamente del hashtag (Imagen 1). Esto puede entenderse como el uso de un objeto externo (un aditamento) que reenvía a un campo semántico diferente al asociado al sujeto. Mientras que Darthés estaba asociado, al menos para una parte de la audiencia, con un campo semántico ligado al acoso, enarbolar un cartel con la consigna de las movilizaciones feministas situaba al actor, por metonimia, en una posición opuesta: acompañando el reclamo de las mujeres.

Imagen 1. Darthés en spot publicitario (izq.) y tuit de apoyo al \# Niunamenos (der.).
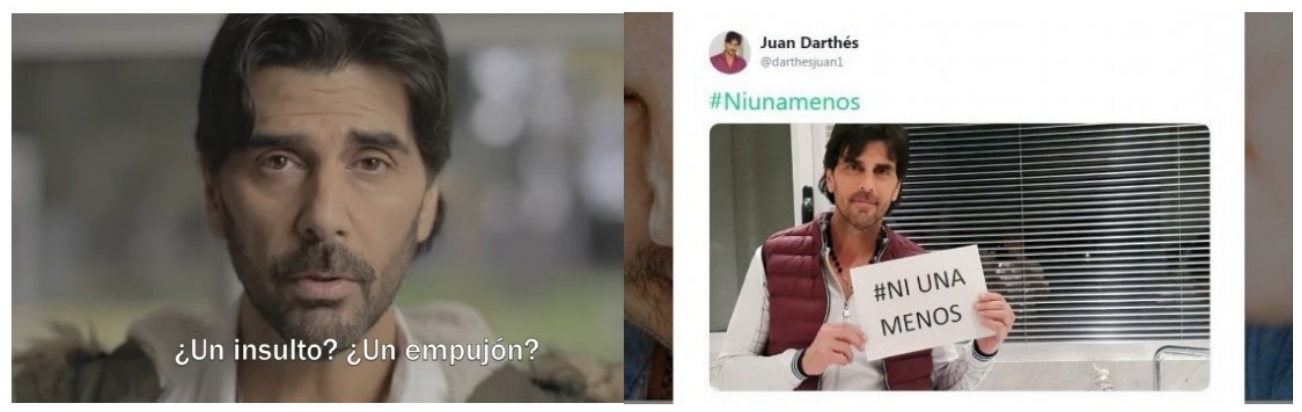

Fuente: Dominio público.

El segundo de los actos ocurrió un año después, cuando el Ministerio de Desarrollo Social lanzó una serie de spots televisivos con el fin de visibilizar la violencia de género y dar a conocer la línea telefónica gratuita para la atención a víctimas. En uno de los spots participó Darthés junto a otras ocho personalidades del mundo del espectáculo. Con una duración de 30 segundos, la presencia del actor resulta efímera: apenas dos segundos de mirada a cámara con la pregunta retórica “¿un insulto?, ¿un empujón?” (Imagen 1). Este hecho se entiende atendiendo al contexto de enunciación: se trata de una participación publicitaria enmarcada en una acción comunicacional de bien público, en la que participan otras figuras del ámbito mediático, tanto actores como actrices. Por tal motivo, la figura de Darthés queda asociada a un enunciador progresista, de naturaleza colectiva y mixta, y empático con la búsqueda de la igualdad de género.

Como veremos a continuación, dicha participación, al igual que su tuit, cobran relevancia al resignificarse a posteriori tras las denuncias de las actrices. Hasta ese momento, la imagen pública de Darthés no estaba 

su figura los rumores sobre su trato a Calu Rivero en 2013, los mismos que fueron desmentidos ese año por la propia actriz. Sin embargo, la trayectoria de Darthés viró a finales de 2017.

El 11 de noviembre, en el programa radial Agarrate, Catalina (AM 1110), conducido por Catalina Dlugi y Silvana Amato, Calu Rivero revivió el debate al confirmar efectivamente haber sufrido acoso por parte de Darthés. La entrevista radial giraba en torno a las denuncias recientes en contra del actor estadounidense Kevin Spacey, y en ese tenor, la conductora Dlugi le preguntó a Calu por los rumores sobre el supuesto acoso que recibió en el rodaje de la telenovela Dulce amor. Sin nombrar directamente a Darthés, la actriz aclaró que no sufrió abuso, pero sí acoso sexual, y que eso era lo que quería expresar en su supuesta desmentida; señaló también que, tras un tiempo de reflexión, se consideraba lista para contar lo sucedido. Ante esto, la respuesta del actor en los días posteriores fue comunicarse con la opinión pública a través de su abogada e iniciar contra la actriz una causa judicial por daños y perjuicios.

Al año siguiente, a la denuncia mediática de Rivero se sumaron las de dos actrices, Ana Coacci y Natalia Juncos. La primera denunció a través de Facebook haber sufrido acoso por parte del actor durante el rodaje de la telenovela Gasoleros (1998), mientras que la segunda denunció en los medios haber sufrido acoso durante las grabaciones de la telenovela Se dice amor (2005). La situación llegó a su máxima expresión en 2018, cuando la actriz Thelma Fardin acusó a Darthés (primero en una conferencia de prensa, acompañada por el colectivo Actrices Argentinas, y luego con una denuncia penal) de abuso sexual durante una gira latinoamericana del elenco de la telenovela Patito feo (2009), cuando ella era menor de edad.

A partir de ese momento, la presión de la opinión pública (de la cual se hicieron eco la mayoría de los/as periodistas) se posicionó del lado de Fardin y fueron expuestas las acusaciones que se acumulaban desde la salida de Calu Rivero de Dulce amor. También, el tuit del actor y su participación en el spot publicitario fueron resignificados y tachados de oportunistas. Ante esto, Darthés se vio obligado a romper el silencio en una entrevista televisiva de 10 minutos con el periodista Mauro Viale (Imagen 2) (A24com, 2018). 
Imagen 2. Darthés en entrevista con Mauro viale.

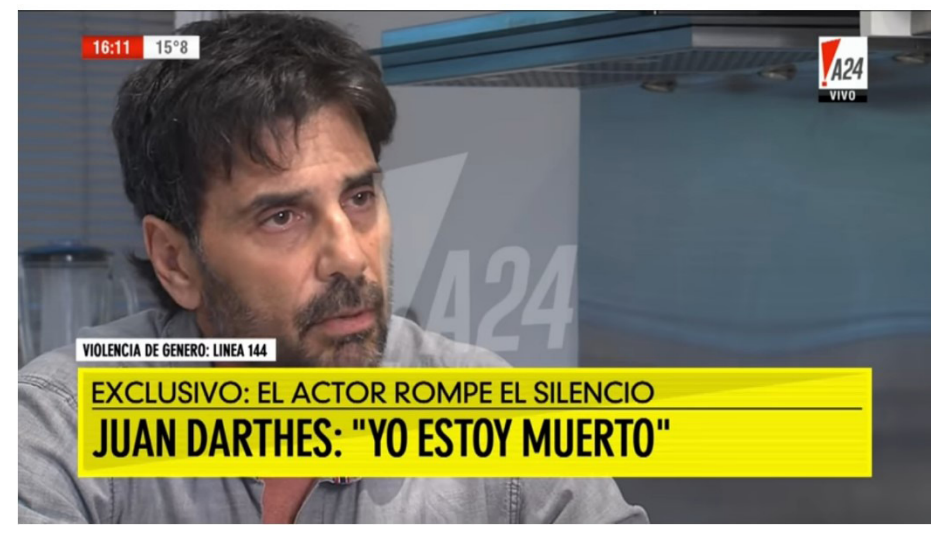

Fuente: A24.

Atendiendo a la dimensión corporal en el contexto de la entrevista (grabada en vivo, pero transmitida en diferido), es posible observar el infructuoso intento de Darthés por mantener el proceso de resemantización: si bien afirmó estar "muerto", también dijo sentirse "indignado", al tiempo que negó todas las acusaciones en su contra, e incluso señaló indirectamente a la actriz como la responsable de lo sucedido. Actualmente, Darthés está exiliado en Brasil, mientras se lleva adelante su proceso penal.

\section{El "deconstruido" Jorge Rial}

El conductor de televisión abierta Jorge Rial (58 años) ha estado históricamente vinculado a escándalos, excesos de poder y un ethos (González Domínguez, 2010, pp. 117-119) ampliamente señalado como violento. El conductor consolidó su posición en el campo mediático gracias a la conducción del ciclo Intrusos en el espectáculo, programa vespertino de periodismo de espectáculos que se emite de lunes a viernes por la señal de televisión abierta América TV. El mismo vio aire en la temporada 2001 y, aun hoy, mantiene su capacidad de influir en la agenda mediática.

El programa Intrusos presentó desde su génesis un formato de panel en el cual el conductor, parado o sentado, dirige los debates que se plantean, acompañado siempre por un grupo estable de panelistas e invitados. La función de estos últimos consiste en poner de relieve los temas que conforman la agenda del programa a partir de dos modalidades: como portadores de información exclusiva o valiosa en lo que refiere al tema abordado, o a modo de evaluadores/comentaristas de la noticia en discusión (Sciurano y Rubinstein, 2017, pp. 689 y ss.). La dinámica del programa sitúa al conductor en un lugar de autoridad desde el cual ejerce el poder de 
manera discrecional y arbitraria: el poder de disponer de información potencialmente perjudicial para terceros, cuya vida privada es expuesta bajo una lógica invasiva y muchas veces violenta.

El proceso de resemantización al que referimos en esta trayectoria puede ilustrarse con la significación en torno a los aditamentos y el contexto de enunciación en el que se desenvuelven.

La primera de ellas, como hemos visto, refiere al nivel de los objetos o aditamentos que el sujeto incorpora a su cuerpo y que operan en la relación intersubjetiva con base en su significado socialmente compartido. En esta categoría podemos encontrar un caso de gran interés: la utilización del pañuelo verde (símbolo de la Campaña Nacional por el Derecho al Aborto) durante la emisión del 2 de febrero de 2018 (Imagen 3), en un momento en el que se discutía en el Congreso Nacional la sanción de una ley para la interrupción voluntaria del embarazo.

Imagen 3. Jorge Rial con pañuelo verde. 2 de febrero de 2018.

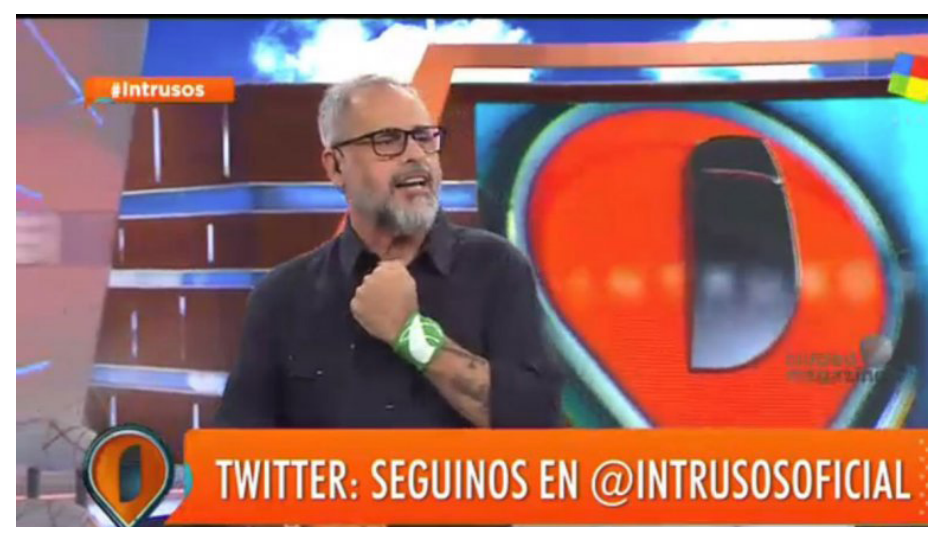

Fuente: América TV.

Ahora bien, para que el proceso de resemantización se consolidara, era necesario también modificar la agenda del programa; es así como en ese mismo periodo se ubica el tratamiento de temas relativos a la desigualdad de género dentro del mundo del espectáculo, con la participación de reconocidas figuras del feminismo en Argentina. El contexto de enunciación del programa viró: salió de la temática habitual, relativa a los rumores del "mundo del espectáculo", para habilitar otro tipo de discusión (la desigualdad de género) y otro tipo de interlocutores. De esta ronda de invitadas vale la pena destacar la participación de la politóloga y comunicadora Florencia Freijo, quien proporcionó un recorrido histórico por el movimiento feminista, así como por sus luchas reivindicativas y 
sus consignas. Asimismo, fue importante la participación de la periodista Luciana Peker y en esta Rial se comprometió a llevar al programa el debate sobre la despenalización del aborto.

Como veremos, la resemantización de la figura de Rial no fue lineal ni estuvo libre de resistencias. Un acontecimiento clave para entender este punto fue el affair (Boltanski, 2014, pp. 50-51) protagonizado por el conductor y la panelista Marcela Tauro en la emisión del 1. ${ }^{\circ}$ de marzo de 2018 (El Wilson, 2018a). Siguiendo la ya detallada lógica del programa, el conductor interpeló a las/os panelistas por el contenido de un informe que versaba sobre las denuncias de acoso de varias actrices que en aquel momento recibía Darthés, y si ellas también habían sufrido acoso. Ante el silencio de Tauro, la insistencia del conductor recibió una réplica inesperada: "No solamente es el acoso, ¿entendés, Jorge?, ¿si yo me sentí incómoda? Sí, hasta trabajando con vos me sentí incómoda, y vos lo sabés. Por eso es un tema que me hace mal hablar". Visiblemente incómodo y para salir del lugar en el que el devenir de la conversación lo dejaba, Rial afirmó “... te sentiste mal porque nos peleamos", ante lo cual Tauro replicó “... claro. Por maltrato”.

La situación, sorpresiva y notoriamente incómoda para quienes allí se encontraban, no pudo desarrollarse debido a que inmediatamente había una tanda de anuncios publicitarios y, tras esta, el cierre de la emisión. A pesar de que la vuelta de la tanda y despedida del programa encontró al conductor abrazado con la panelista (Imagen 4), la situación fue rápidamente amplificada y replicada por la prensa gráfica, radial y televisiva. Basta con buscar las palabras en Google "Rial, Tauro, maltrato" para hallar más de 30.000 resultados.

Imagen 4. Jorge Rial abraza a Marcela Tauro. 1. ${ }^{\circ}$ de marzo de 2018.

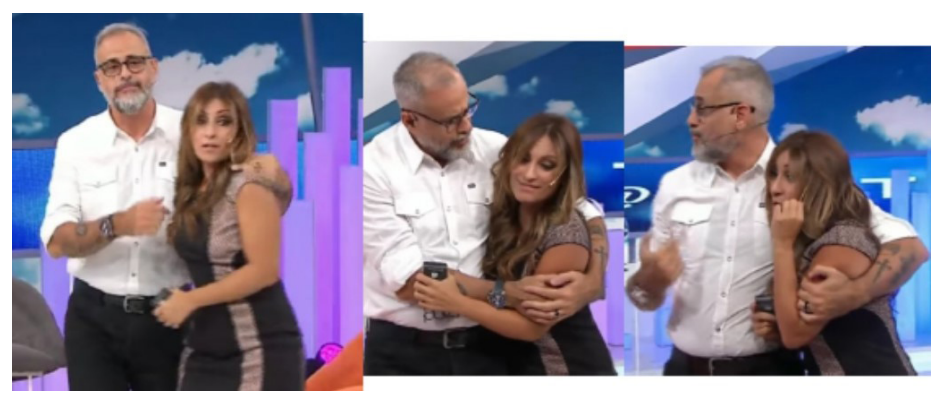

Fuente: América TV.

Hay que analizar aquí la corporalidad: al observar el modo en que se produjo, es posible apreciar que no se trató de un abrazo entre dos sujetos, sino que fue una acción unidireccional; es decir, Jorge Rial no se abrazó "con" 

una situación en la que conscientemente un sujeto intenta mostrar una imagen de conciliación para evitar la confusión de los terceros (Tusón Valls, 2002). Es evidente la incomodidad de la panelista, quien se dejó abrazar sin realizar contacto visual con el conductor ni con la cámara, lo que revela la asimetría de poder y el ejercicio unidireccional de las interacciones, que caracterizaban tradicionalmente a Jorge Rial.

El hecho adquirió estatus de escándalo y pasó a ocupar un lugar en la agenda pública. Tanto fue así que Rial tuvo que aclarar durante la siguiente emisión lo que había acontecido. Este proceso posterior da lugar al reajuste entre la figura de Rial (en el centro de los cuestionamientos sociales) y el campo semántico que estaba construyendo; en este reajuste también participa la propia Marcela Tauro.

En la emisión subsiguiente al hecho narrado, Tauro y Rial enmarcaron la situación dentro del ámbito laboral, dejando así de lado cuestiones relativas a la misoginia o el sexismo. En el comienzo del programa, hablando tanto a los espectadores como al propio Rial, la panelista aseveró que “... generalmente, estas discusiones son completamente normales entre Jorge y yo, y siempre que puedo te contesto" (El Wilson, 2018b). Por su parte, el conductor agregó que su accionar ya no se encuadraba en la violencia de género: "No creo ser un maltratador. He tenido épocas de calentón, pero ahora por suerte estoy cambiando" (El Wilson, 2018b).

\section{El empresario Marcelo Tinelli}

Si hay un arquetipo de éxito televisivo en la Argentina en las últimas tres décadas, ese es Marcelo Tinelli (60 años), un faro de la escena pública nacional, con un campo de influencias que se asienta en lo mediático, pero que también lo trasciende: es presidente del club San Lorenzo, cuyo equipo de fútbol participa de la primera división, y ocupó cargos de alta responsabilidad en la Asociación del Fútbol Argentino. Como empresario, es presidente fundador de una de las productoras de medios más grandes del país y ha sido dueño, accionista y productor de contenidos en las más importantes productoras nacionales. Su influencia se extiende incluso a escala regional, ya que contenidos creados por él han ocupado la pantalla chica de varios países, a los cuales llegó a exportar formatos televisivos.

Además de presidir su propia fundación y tener cargo ejecutivo en un club, Tinelli es conductor desde hace 30 años del programa más exitoso de la televisión abierta argentina, retransmitido con gran impacto en casi toda América Latina (Heram, 2018). Showmatch (ex-Videomatch), bajo su formato de reality show Bailando por un sueño, ha convertido a Tinelli en una figura 
pública omnipresente, a la que se atribuye una nada despreciable influencia política (Gandolfo, 2013). En este sentido, son ejemplos destacados su presunta contribución a la caída del presidente Fernando de la Rúa en 2001 (Carlón, 2016) o a la victoria del empresario Francisco de Narváez en las elecciones legislativas de 2009. No en vano, cada vez que una crisis de legitimidad azota al sistema de partidos políticos y a sus representantes tradicionales, Tinelli se convierte en el primer candidato presidenciable outsider, cuya popularidad muchos se dedican a medir en encuestas de opinión pública.

En suma, se trata de un personaje que suscita un doble interés disciplinar: en cuanto productor de contenidos y propuestas culturales, se lo puede ver desde una perspectiva estética, mientras que al mismo tiempo, y a causa del éxito en el plano mediático, su figura reviste interés para el análisis político (Martínez Mendoza, 2009). A pesar de su lugar de preeminencia, Tinelli se vio llevado, al igual que el resto de las figuras públicas, a operar sucesivos corrimientos para reposicionarse frente a la ola originada por el movimiento de mujeres y sus múltiples derivas.

La descripción sumaria de la carrera televisiva de Tinelli vista en relación con el tratamiento de la cuestión de género puede dividirse en tres momentos: uno (visto desde la actualidad) machista-misógino, otro de transición y un último de realineamiento de valores. Sostendremos, además, que el conductor viene transitando (al menos provisoriamente) un sendero de exitosa resemantización; esto es, ha logrado ponerse a resguardo de críticas y denuncias de género, incluso a pesar de su trayectoria y la de su programa, y consiguió con eficacia que su figura y el espacio que ocupa se desprendieran del campo semántico al cual estaba antaño engarzado. A continuación describimos las etapas de tal trayectoria.

Si bien la palabra "misoginia" es enfática, no cabría mejor descripción a la primera etapa mediática del conductor, la cual se extendió en el tiempo durante un período considerable. Dos prácticas son representativas de aquel período, que va desde el inicio de la carrera de Tinelli hasta 2014/2015: los sketches de Videomatch/Showmatch entre 1990 y 2009, para los cuales el conductor fungía, además, de productor, y el cortado de polleras en Showmatch dentro de su formato Bailando por un sueño entre 2009 y 2014.

En los sketches fueron dominantes durante este primer ciclo las cámaras ocultas, las cuales encontraban dos modalidades: o bien se las hacía a personas no famosas, con colaboración de las familias yactores desconocidos, o se las hacía a figuras del espectáculo con la colaboración de artistas del programa (Mangone, 1992). Notoriamente, en esta última modalidad las víctimas de las cámaras ocultas eran por regla general mujeres. Actrices, 
vedettes, modelos y conductoras que eran engañadas y sometidas a una serie de humillaciones, para luego ser transmitidas en el ciclo televisivo catalogado como "humor". Los registros de archivo abundan y, por tal motivo, no incurriremos en una descripción pormenorizada. Señalamos solamente que estos incluían degradación verbal hacia la mujer (referida a su inteligencia, su cuerpo y su sexualidad), propuestas de dinero a cambio de sexo y exhibicionismo (los actores se desnudaban intempestivamente y perseguían a la víctima de la cámara oculta).

Si bien estas producciones se discontinuaron a partir del advenimiento de Bailando por un sueño, las prácticas vejatorias sobre los cuerpos y la autonomía de las mujeres se mantuvieron constantes. Bajo el nuevo formato, el machismo se cristalizó en la práctica del conductor de cortar polleras de las bailarinas, incluso cuando estas no estaban de acuerdo (Imagen 5). La antropóloga Rita Segato se ha referido públicamente a esta práctica como "una rapiña sobre el cuerpo de las mujeres (...) una lente televisiva que corta polleras..." (La Nación, 2017).²

\section{Imagen 5. Tinelli cortando polleras en una de las emisiones de Bailando por un sueño.}

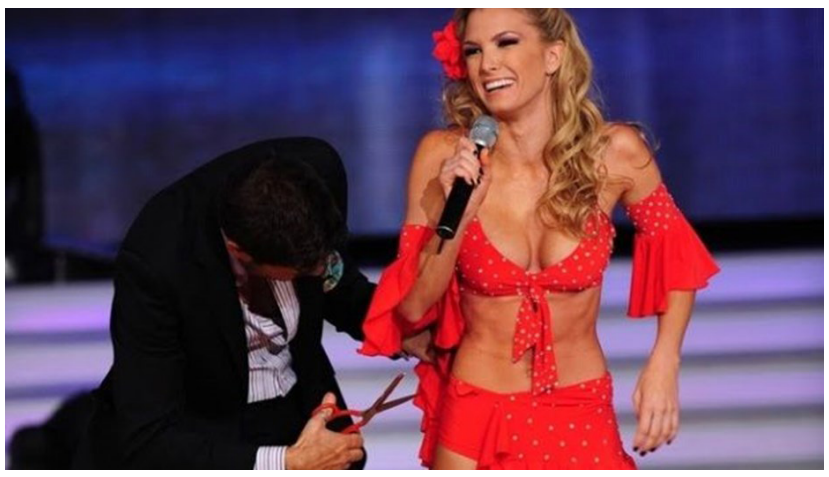

Fuente: Canal Trece.

Como se ha mencionado, en el año 2015, con la llegada del \#Niunamenos se produjo un cambio en la sensibilidad popular que tuvo sus efectos sobre el programa. La violencia machista se convirtió en eje central de debate público y las figuras de los medios se plegaron a la preocupación. En ese contexto, antes del lanzamiento del ciclo anual, Bárbara Vélez denunció a su, en ese entonces, novio Federico Bal (ambos, figuras mediáticas) por violencia doméstica. La coyuntura y el estatus público de ambos protagonistas desencadenaron un escándalo de envergadura. La producción encaraba un dilema entre tomar a ambos participantes en el certamen y garantizarse
2 El término "pollera" es un regionalismo (Argentina, Uruguay, Paraguay) que se utiliza para designar lo que comúnmente se conoce como "falda". 
un grado supremo de visibilidad y promoción en todos los medios o, por el contrario, dejar a ambos afuera y esperar que se expidiera la justicia.

A pesar de la gravedad de las denuncias penales que corrieron por ambos lados, la producción contrató a las dos figuras y usufructuó la espectacularidad del caso. Consideramos esta como una etapa de transición, en la cual si bien banalizaron el tema y relativizaron las denuncias por violencia (y el acusado fue a la postre campeón del certamen), dejaron de cortar polleras y matizaron las prácticas y expresiones machistas del conductor y sus colaboradores. La metamorfosis en la posición del ciclo frente a las problemáticas de género siguió, a partir de allí, mutando en la misma dirección.

Encontramos el hito de dicha metamorfosis en la emisión del 18 de diciembre de 2018 (El Indio, 2018), en la cual el ciclo se apropió del clima de época y adoptó el carácter simbólico de plataforma para la denuncia pública y problematización de distintas formas de violencia contra las mujeres. En un clima social de alta sensibilidad por la reciente denuncia de violación que hiciera Thelma Fardin (descripta oportunamente), una de las concursantes de Bailando por un sueño declaró en vivo que estaba sobrepasada de emociones y que había sufrido abuso sexual a los 11 años por parte de una persona cercana. Personal del programa, junto a Tinelli, contuvieron a la actriz y modelo, en un espacio amigable y propicio para la escucha, contención, visibilización y repudio de vejámenes contra la integridad de las mujeres. El conductor, visiblemente emocionado, la dejó hablar y al finalizar la abrazó; inmediatamente después, hicieron uso de la palabra una miembro del jurado y el marido de la modelo. La escena, que no dura más de siete minutos, concluye con un abrazo de las mujeres del jurado a la participante, al cual se pliegan las bailarinas y mujeres presentes en el set (Imagen 6).

\section{Imagen 6. Plano medio hombros de Marcelo Tinelli durante la declaración de la concursante Mery del Cerro en la emisión del 18 de diciembre de 2018.}

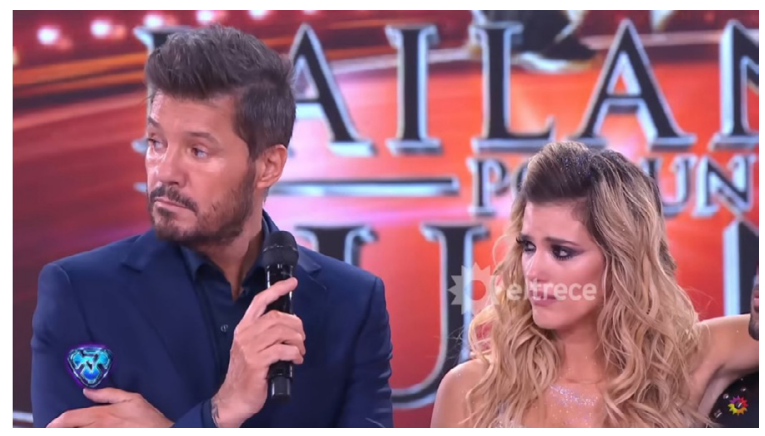

Fuente: Canal Trece. 
Esta emisión permite captar en un solo movimiento la puesta en funcionamiento de la resemantización a través del espacio de enunciación y de la corporalidad. En el primer caso, si bien la situación fue imprevista (dado que la emisión es en directo), permitieron que la concursante Mery del Cerro se explayara sin interrupción y que los otros sujetos intervinieran para dar su apoyo. El espacio del programa ya no estaba con el ethos del concurso, sino que mutó en esos minutos en un ámbito de denuncia y contención. A su vez, el mismo carácter de imprevisibilidad se manifestó en el desborde del sentido de la corporalidad de los sujetos: tanto Tinelli como el resto del personal se vieron conmocionados y debieron ajustar su comportamiento a la situación que abrió la declaración de la concursante (Imagen 6). Por su parte, el conductor se limitó a acompañar el desarrollo de la situación sin intervenir directamente.

El proceso de resemantización no terminó en dicho episodio. Al año siguiente, 3 de marzo de 2019, en una entrevista radial con Matías Martin para el programa Basta de todo (FM Metro 95.1), el conductor reconoció sentir "vergüenza" por los actos del corte de pollera (Tinelli, 2019). Asimismo, aprovechó para defender su programa de quienes le recriminaban dichas acciones alegando que se trataba de un problema estructural "de toda la sociedad". De esta forma asumió éticamente una crítica a su accionar, aunque enfatizando que no es el único, y, además, lo separó de la gestión laboral y económica de los contenidos audiovisuales que produce.

\section{Conclusiones}

Como hemos visto, la presión social de las marchas y movilizaciones de mujeres ha fungido como condición de producción que explica el proceso de resemantización de figuras mediáticas centrales en el campo televisivo argentino. Dicho proceso no es homogéneo ni lineal, sino que su éxito depende de las relaciones de poder que entran en juego, muchas veces previas y de largo arraigo, y que quedan en relieve a partir de las trayectorias analizadas. Simplificando la lógica del modelo propuesto, podemos afirmar:

- En el caso de Darthés, quien con base en su condición de actor solo posee capital específico, aunado a la gravedad de las denuncias de las actrices, el proceso de resemantización se vio bloqueado.

- Por otra parte, Rial se encuentra en un punto medio: posee más que capital específico, pero no ostenta el mismo peso que Tinelli, por lo que su proceso de resemantización, luego del affaire con Marcela Tauro, debió ser reajustado.

- Finalmente, Tinelli posee no solo capital específico (en cuanto conductor), sino también burocrático (en cuanto productor audiovisual, tomador de 
decisión de un importante club de fútbol y potencial candidato político), por lo que su proceso de resemantización ocurre casi sin contratiempos.

En este punto reafirmamos una apuesta analítica que se traduce en una propuesta metodológica: es preciso complementar los datos cuantitativos empleados para medir las desigualdades dentro del campo mediático con otro tipo de datos que ahonden en el carácter procesual del fenómeno y den cuenta de sus especificidades. Los métodos para la producción de datos cuantitativos, predominantes en los estudios de género y medios desde la década de 1970 para describir el cuadro de situación, deben ser acompañados con herramientas analíticas que permitan comprender las causas, y así conocer tanto el qué (el lugar de subalternidad de las mujeres en los medios de comunicación) como el cómo (en este caso, procesos de resemantización que habilitan la reproducción de jerarquías de género). No se trata meramente de reseñar estrategias oportunistas, sino de poner en evidencia la historicidad de procesos cuya invisibilidad es condición necesaria para sostener el statu quo.

Una mirada panorámica sobre el funcionamiento de los medios en el mundo pone de manifiesto que la desigualdad que hemos abordado trasciende el ámbito local. Es sabido que ciertas desigualdades son más proclives que otras a encuadrar dentro de fronteras estatales o regionales: alli donde el ingreso per cápita puede ser explicado eficazmente apelando a la dimensión geográfica, las desigualdades enraizadas y estructuradas en torno a la construcción social de la diferencia sexual tienden a ser transversales. El género constituye una dimensión de segregación tanto en el Norte como en el Sur Global, y se expresa en múltiples indicadores: remuneración diferencial respecto de los varones para tareas equivalentes, dificultades en el acceso a altas jerarquías organizacionales (techo de cristal), distribución inequitativa de tareas de reproducción doméstica y cuidado; todas, aunque en distinto grado, pueden constatarse en Argentina y Suecia, Chile y España, Colombia y Estados Unidos. La televisión, está claro, no escapa a esta lógica y la reproduce a partir, por ejemplo, del mecanismo que hemos abordado en el artículo, posible de ser aplicado para el análisis en otras latitudes.

Quedapordelanteemprenderestudiosquedencuentadelosentrelazamientos de la resemantización (en cuanto mecanismo perpetuador de la desigualdad simbólica) con otras formas de reproducción de desigualdades de género en el campo mediático en general, y en el televisivo en particular. 


\section{Referencias}

A24com. (2018). EXCLUSIVO: La versión de Juan Darthés con Mauro Viale [Video]. YouTube. https: / / www.youtube.com/watch?v=04Ur4V1XfGQ\&ab_channel=A24com

Boltanski, L. (2014). De la crítica. Ediciones Alka.

Bourdieu, P. (1996). Sobre la televisión. Editorial Anagrama.

Carlón, M. (2004). Sobre lo televisivo. La Crujía Ediciones.

Carlón, M. (2016). Después del fin. Una perspectiva no antropocéntrica sobre la post-tv, el post-cine y YouTube. La Crujía Ediciones.

Chenou, J. M. y Cepeda-Másmela, C. (2019). \#NiUnaMenos: Data activism from the Global South. Television er New Media, 20(4), 396-411. doi:10.1177/1527476419828995. https:// journals.sagepub.com/doi/abs/10.1177/1527476419828995

Corcuff, P. (1998). Las nuevas sociologías. Alianza Editorial.

Eco, U. (2016) [1976]. Tratado de semiótica general. Editorial Debolsillo.

El Indio. (2018, diciembre 13). Mery del Cerro reveló que fue abusada y SE QUEBRÓ EN VIVO - Bailando 2018 Showmatch 2018 [Video]. YouTube. https://www.youtube.com/ watch?v=oshdnDDBRfM

El Wilson. (2018a, marzo 1). Tensión al aire entre Marcela Tauro y Jorge Rial: "me sentí incómoda laburando con vos por maltrato" [Video]. YouTube. https:/ / www.youtube. $\mathrm{com} /$ watch?v=CYdinpvxkql

El Wilson. (2018b, marzo 2). El descargo de Jorge Rial tras el tenso cruce con Marcela Tauro [Video]. YouTube.

https:// www.youtube.com/watch?v=nbTVuL9OVvc

Faur, E. (2017) Mujeres y varones en la Argentina de hoy: Géneros en movimiento. Siglo Veintiuno Editores.

Gago, V. (2019). El cuerpo del trabajo. Tres escenas cartografiadas desde el paro feminista. A Contracorriente: una revista de estudios latinoamericanos, 16(3), 39-60. https://dialnet. unirioja.es/servlet/articulo? codigo $=6974096$

Gandolfo, A. (2013). La más conflictiva música: Tinelli, Showmatch y el pueblo argentino. Mancilla, 5(6), 94-99. https://ri.conicet.gov.ar/handle/11336/26908

García Beaudoux, V. (2018). Una tipología de los sesgos y estereotipos de género en la cobertura periodística de las mujeres candidatas. Revista Mexicana de Opinión Pública, 13(24), 113-129. doi:10.22201/fcpys.24484911e.2018.24.61614. http://www.scielo.org.mx/ scielo.php?script=sci_arttext\&pid=S2448-49112018000100113

González Domínguez, C. (2010). El ethos del conductor del noticiario televisivo. Una comparación entre Francia y México. Convergencia, Revista de Ciencias Sociales, (54), $111-134$.

Heram, Y. (2018). ¿Por qué Showmatch? Un acercamiento al consumo televisivo de uno de los programas más vistos en Argentina. Fonseca, Journal of Communication, (16), 171-184. doi:10.14201/fjc201816171184. https:// revistas.usal.es/index.php/2172-9077/article/view/ fjc201816171184

Jelin, E., Motta, R. y Costa, S. (2017). Global entangled inequalities conceptual debates and evidence from Latin America. Routledge. 
Jelin, E., Motta, R. y Costa, S. (2020). Repensar las desigualdades: cómo se producen y entrelazan las asimetrías globales (y qué hace la gente con eso). Siglo XXI Editores.

Krijnen, T. (2020). Gender and media. En Ross, K. (Ed.), The International Encyclopedia of Gender, Media, and Communication. John Wiley \& Sons Inc. doi:10.1002/9781119429128. iegmc016

La Nación (2017). Rita Segato explica qué pasa por la cabeza de un violador [Video]. YouTube. https: / / www.youtube.com/watch?v=GwKOMw9EITA

Leunda, A. I. (2015). Semiótica de la cultura y retórica del cuerpo: puentes disciplinares desde/sobre América Latina. AdVersus, Revista de Semiótica, 13(29), 67-90. https:/ / dialnet.unirioja.es/servlet/articulo?codigo=5981419

López Mujica, J. M. (2011). Masa, TV y poder: Tinelli o el héroe posmoderno. Question, 1(32). https: / / dialnet.unirioja.es/servlet/articulo? codigo=5702256

Maier, C. (2008). Traducción corpórea: meditaciones sobre la mediación. DeSignis. Traducción/Género/Poscolonialismo, (12), 41-48.

Mangone, C. (1992). Tinelli. Un blooper provocado. La Marca Editora.

Martínez Mendoza, R. (2009). Buenas noches, América. Acerca de la televisión, su cotidianeidad y su muerte. Figuraciones, Teoría y Crítica de Arte, (6). https: / / repositoriosdigitales.mincyt.gob.ar/vufind/Record/ RIDUNA_706bb237b69fd9684ac80c732e6af1ca

Pontes, F. S. (2017). Desigualdades estruturais de gênero no trabalho jornalístico: o perfil das jornalistas brasileiras. E-Compós, 20(1). doi.org/10.30962/ec.1310. https://www.ecompos.org.br/e-compos/article/view/1310

Reygadas, L. (2020). La construcción simbólica de las desigualdades. En E. Jelin et al. (Eds.), Repensar las desigualdades (pp. 201-222). Siglo XXI Editores.

Sciurano, G. A. y Rubinstein, I. F. (2017). Desfasajes entre visibilidades y discursos televisivos: el aporte de la semiótica a los estudios de género y medios. En N. Pardo Abril y L. E. Ospina Raigosa (Comps.), Miradas, lenguajes y perspectivas semióticas. Aportes desde América Latina (pp. 683-696). Instituto Caro y Cuervo, Universidad Nacional de Colombia. Tinelli, M. (2019, marzo 3). Entrevista en el programa Basta de todo (FM Metro 95.1) [Transmisión de radio].

Tusón Valls, A. (2002). El análisis de la conversación: entre la estructura y el sentido [PDF]. Estudios de Sociolingüística, 3(1), 133-153. https:/ / www.textosenlinea.com.ar/ academicos/El\%20an\%C3\%A1liis\%20de\%20la\%20conversacion.pdf

Vega Montiel, A. (2014). Igualdad de género, poder y comunicación: las mujeres en la propiedad, dirección y puestos de toma de decisión. La Ventana, 5(40), 186-212. http:// www.scielo.org.mx/scielo.php?script=sci_arttext\&pid=S1405-94362014000200008 Verón, E. (1998). La semiosis social. Fragmento de una teoría de la discursividad. Editorial Gedisa. 